\section{Anxiety and the risk of death in older men}

\section{and women}

\author{
HEIN P. J. VAN HOUT, AARTJAN T. F. BEEKMAN, EDWIN DE BEURS, \\ HANNIE COMIJS, HARM VAN MARWIJK, MARTEN DE HAAN, \\ WILLEM VAN TILBURG and DORLY J. H. DEEG
}

\begin{abstract}
Background There are inconsistent reports as to whether people with anxiety disorders have a higher mortality risk.
\end{abstract}

\begin{abstract}
Aims To determine whether anxiety disorders predict mortality in older men and women in the community.
\end{abstract}

Method Longitudinal data were used from a large, community-based random sample $(n=3107)$ of older men and women (55-85 years) inThe Netherlands, with a follow-up period of 7.5 years. Anxiety disorders were assessed according to DSM-III criteria in a two-stage screening design.

Results In men, the adjusted mortality risk was 1.78 (95\% Cl I.0I-3.13) in cases with diagnosed anxiety disorders at baseline. In women, no significant association was found with mortality.

Conclusions The study revealed a gender difference in the association between anxiety and mortality. For men, but not for women, an increased mortality risk was found for anxiety disorders.

Declaration of interest None.
Although the elevated mortality risk in depression is well established (Cuijpers, 2001), comparable studies of the risks of anxiety are sparse and inconsistent (Coryell et al, 1986; Johnson et al, 1990; Weissman et al, 1990; Allgulander \& Lavori, 1991; Herrmann et al, 2000; Warshaw et al, 2000; Joukamaa et al, 2001). An explanation for the inconsistency of reported mortality risks of patients with anxiety disorders may be the failure to control for the effects of comorbid depression, socioeconomic status and unhealthy lifestyles in some studies. These variables are related both to anxiety disorders and to subsequent mortality, and may cause spurious relationships between anxiety and mortality (Honig et al, 1992; Lasser et al, 2000).

The main objective of this study was to determine whether anxiety disorders predict mortality in older people in the community. Subsidiary objectives were to filter out the effect of comorbid depression, to compare men and women, and to explore the effects of potential explanatory (lifestyle) and confounding variables.

\section{METHOD}

\section{Design and sample}

Data were collected in the context of the Longitudinal Aging Study Amsterdam (LASA). This is an ongoing longitudinal research effort on determinants and consequences of changes in well-being and autonomy in older people. The analyses were based on the data of 659 independently living community residents. Data collection procedures and response have been described in more detail elsewhere (Beekman et al, 1995a; Geerlings et al, 2000). In short, a random sample was drawn from the population registers of 11 municipalities in three geographic areas in The Netherlands. At baseline 3805 residents, aged 55-85 years, were approached to participate in the study. This sample was pre-stratified by age and gender. The older age strata and men were oversampled in anticipation of higher attrition rates during the course of the study. Owing to initial non-response $(n=698)$ and item non-response $(n=51), 3056$ persons were interviewed at baseline. These participants gave their informed consent and agreed to be interviewed in their homes. Of the non-responders, 126 had died before approach; 44 could not be contacted, 134 were too ill or cognitively impaired to be interviewed, and 394 were unwilling to participate (Van Exel et al, 2000).

Participants with anxiety disorders were identified using a two-stage screening design (Duncan-Jones \& Henderson, 1978). The Center for Epidemiological Studies Depression Scale (CES-D; Radloff, 1977) was used as the screening instrument, using the generally recommended cut-off score of 16 or over. This scale was found to be a good screen for both anxiety and depression (sensitivity 0.79). The second stage of case-finding involved a diagnostic interview, held 2-8 weeks after the first LASA assessment, with everyone who screened positive and an equally large random subsample of participants who screened negative. The response at this stage was $86.0 \%$ and attrition was related to age but not to gender, leaving a study sample of 659 persons interviewed, of whom 332 were 'screen positives' and 327 'screen negatives' (Beekman et al, 1995b).

Informed consent was obtained from everyone who participated in the study. Participants were interviewed in their homes by well-trained and intensively supervised interviewers. These interviewers were trained to conduct only the baseline assessment or the diagnostic interview, ensuring that no participant was interviewed by the same person twice.

\section{Measurements}

\section{Psychopathology}

Both anxiety disorders and comorbid major depressive disorder were defined according to DSM-III criteria (American Psychiatric Association, 1980) and assessed by means of the Diagnostic Interview Schedule (DIS; Robins et al, 1981). In this study four anxiety disorders were assessed: phobic, panic, generalised anxiety and obsessivecompulsive disorders. The analyses were based on anxiety disorders and major depression experienced in the 6 months prior to interview. 


\section{Death}

Death certificates were traced through the registries of the municipalities in which the respondents were registered. Vital status ascertainment was complete. All deaths were recorded that occurred between the baseline interview (September 1992 to September 1993) and 1 January 2000. The average follow-up period lasted 7.5 years $($ s.d. $=0.3)$.

\section{Covariates}

Potential explanatory variables included the lifestyle variables smoking, drinking, body mass index and physical activity (walking, cycling, light and heavy household activities, and sports; Visser et al, 1997).

Potentially confounding or effectmodifying variables, assessed at the study baseline, included demographic characteristics (age, gender, socio-economic status, marital status and urbanisation). As a measure of socio-economic status we used a weighted score composed of level of education, occupation and income (range 0-100) (van Tilburg et al, 1995; Visser et al, 1997). Psychiatric treatment status was measured and concerned contacts with a psychiatrist or psychological and appropriate psychotropic medication. An earlier account described the treatment rates (de Beurs et al, 1999). Functional limitations (restrictions in performing daily physical activities) were measured using an adaptation of an Organisation for Economic Co-operation and Development (OECD) questionnaire (van Sonsbeek, 1988). Cognitive functioning was assessed with the Mini-Mental State Examination (Folstein et al, 1975). Chronic physical diseases were assessed in detail, including cardiac diseases, arteriosclerosis, stroke (excluding transient ischaemic attacks), diabetes mellitus, cancer, lung diseases (chronic obstructive pulmonary disease) and arthritis. Other chronic diseases were assessed in less detail. The validity of the instrument was supported in a previous study by crosschecking responses with the respondents' general practitioners (Kriegsman et al, 1996; Visser et al, 1997).

\section{Statistical analyses}

The socio-demographic, morbidity, treatment status and lifestyle characteristics of survivors and deceased were compared by means of $\chi^{2}$ or $t$-tests. Mortality rates per
1000 person-years were calculated according to anxiety status. When the $95 \%$ confidence intervals of the hazard ratio did not include the value 1 , the association was considered to be statistically significant.

Cox proportional hazard regression models were used to examine the association between anxiety disorders and time to death in men and women and with adjustment of the explanatory (lifestyle) and confounding variables (age, disease, disability, cognition). We explored potential effect modification of the relation between anxiety and mortality by the socio-demographic, comorbid depression, physical morbidity, physical disability, cognitive functioning and lifestyle variables, by interactions in Cox survival models. For the same variables we checked whether these confounded the relation between mortality and anxiety. Significant interaction was only found between gender, anxiety and mortality. The survival curve for men showed a positive association between anxiety and mortality rate, whereas for women it did not. We therefore present the outcomes separately for men and women. Also the confounders were analysed separately for men and women.

Additional sensitivity analyses were performed to investigate whether the effects were maintained when controlling for depression (both for depressive disorder and depressive symptoms) and for ongoing psychiatric treatment.

\section{RESULTS}

\section{Characteristics of the sample}

The mean age of the 659 respondents was 70.6 years; $380(57.6 \%)$ were women. In the study sample $112(17.0 \%)$ had an anxiety disorder. Nineteen persons $(3.1 \%)$ had more than one anxiety disorder and $29(4.4 \%)$ had both anxiety and depressive disorders. Generalised anxiety disorder was present in the previous 6 months in 77 persons, panic disorder in 16 persons, phobia in 36 persons and obsessivecompulsive disorder in 9 persons (all 9 were women) (Table 1). Extrapolation of the 6month prevalence of anxiety disorders to the entire LASA study sample yielded an estimated prevalence of $10.2 \%$ (Beekman et al, 1998). The baseline characteristics differed between men and women on several variables. Notably more women than men suffered from anxiety disorders and comorbid depression; men suffered more from cardiac diseases, stroke and chronic obstructive pulmonary disease; considerably more men smoked than women.

Compared with the non-anxious group, people with an anxiety disorder were older, more likely to be female, less likely to be married, more often living in urban areas, had lower socio-economic status, suffered more from chronic physical illnesses and were less physically active. The number of anxious persons treated by a psychiatrist or psychotropic medication was low (Table 1). Women with anxiety disorder were more likely to be treated at follow-up than men.

After 7.5 years, in total $199(30.2 \%)$ persons had died. Of the men, 110 $(39.4 \%)$ had died compared with 89 $(23.4 \%)$ of the women. Univariate analyses between mortality and socio-demographic characteristics, chronic diseases, lifestyle and the anxiety screening score at baseline revealed significant associations on all variables except for urbanisation and arthritis. This indicates that the association between anxiety and mortality may be confounded by several variables.

Table 2 shows the number of cases of anxiety, the number deceased, the number of person-years and the mortality rate at 7.5-year follow-up. The unadjusted mortality rates suggest that the mortality risk is (slightly) elevated in respondents with an anxiety disorder. There was a substantial difference between men and women. The gender $\times$ anxiety interaction term in the age-adjusted model was found to be statistically significant (Wald test 6.3 , d.f. $=1$, $P=0.04$ ).

\section{Anxiety disorder and mortality}

Three (potential) confounders were found, and these were similar for men and women: age, functional limitations and the number of chronic diseases. Neither the chronic diseases alone nor cognitive impairment affected the relationship between anxiety and mortality. In our sample, $26 \%$ of people with an anxiety disorder also met criteria for major depression. In men $14.7 \%$ of the patients with anxiety disorder had comorbid depression compared with $31.2 \%$ in women. However, adjustment for baseline depression did not change the mortality risk of anxiety.

Activity level was the only explanatory variable that substantially changed the 
Table I Baseline characteristics and anxiety disorders among men and women (unweighted percentages; $n=659)$

\begin{tabular}{|c|c|c|c|}
\hline & Men $(n=279)$ & Women $(n=380)$ & Difference \\
\hline \multicolumn{4}{|l|}{ Anxiety disorder, $n$ (\%) } \\
\hline Any anxiety disorder past 6 months & $35(12.5)$ & $77(20.3)$ & $\chi^{2}=6.8^{* *}$ \\
\hline Generalised anxiety disorder & $24(8.6)$ & $53(14.1)$ & $\chi^{2}=4.2^{*}$ \\
\hline Panic disorder & $3(1.1)$ & $13(3.4)$ & $\chi^{2}=3.7$ \\
\hline Phobia & $12(4.3)$ & $24(6.3)$ & $\chi^{2}=1.2$ \\
\hline OCD & 0 & $9(2.4)$ & $\chi^{2}=6.6 * *$ \\
\hline More than one anxiety disorder & 3 (I.I) & $16(4.2)$ & $\chi^{2}=8.9$, d.f. $=3^{* *}$ \\
\hline Comorbid depressive disorder, $n$ (\%) & 5 (I.8) & $24(6.3)$ & $\chi^{2}=10.2^{* *}$ \\
\hline Psychiatric treatment, $n$ (\%) & 8 (2.9) & II (2.9) & $\chi^{2}=0.001$ \\
\hline Psychotropic medication, $n$ (\%) & II (3.9) & $26(6.8)$ & $\chi^{2}=5.2^{*}$ \\
\hline \multicolumn{4}{|l|}{ Sociodemographic factors } \\
\hline Age, years: mean (s.d.) & 70.9 (8.8) & 70.5 (8.7) & $t=1,2$ \\
\hline Socio-economic status score: mean (s.d.) & $36.7(18.8)$ & $31.1(19.2)$ & $t=8.1 * * *$ \\
\hline Married, $n(\%)$ & $187(67)$ & $165(43.4)$ & $\chi^{2}=201 * * *$ \\
\hline Urbanised (lived in Amsterdan), $\boldsymbol{n}$ (\%) & $83(29.7)$ & $122(32.1)$ & $\chi^{2}=0.4$ \\
\hline \multicolumn{4}{|l|}{ Morbidity, n (\%) } \\
\hline Any chronic disease & $166(59.5)$ & $260(68.4)$ & $\chi^{2}=8.7$, d.f. $=2^{*}$ \\
\hline Cardiac diseases & $84(30.1)$ & $64(16.8)$ & $\chi^{2}=4 I^{* * *}$ \\
\hline Peripheral arteriosclerosis & $36(12.8)$ & 45 (II.8) & $\chi^{2}=0.3$ \\
\hline Stroke & $21 \quad(7.5)$ & $22(5.8)$ & $\chi^{2}=11.1 * *$ \\
\hline Diabetes & $18(6.4)$ & $39(10.3)$ & $\chi^{2}=1.3$ \\
\hline COPD & $46(16.4)$ & $46(12.1)$ & $\chi^{2}=7.5^{* *}$ \\
\hline Cancer & $25(9)$ & $46(12.1)$ & $\chi^{2}=19.7^{* * *}$ \\
\hline Osteoarthritis & $68(24.4)$ & $179(47.1)$ & $\chi^{2}=133^{* * *}$ \\
\hline Rheumatoid arthritis & $15 \quad(5.3)$ & $33(8.7)$ & $\chi^{2}=25^{* * *}$ \\
\hline \multicolumn{4}{|l|}{ MMSE } \\
\hline Score <24, n (\%) & $27(9.6)$ & $44($ (II.6) & $\chi^{2}=1.7$ \\
\hline Mean score (s.d.) & $26.9(3)$ & $26.9(3)$ & $t=0.4$ \\
\hline \multicolumn{4}{|l|}{ Functional limitations' } \\
\hline Mean score (s.d.) & I.I (2) & $1.8(2.6)$ & $t=-8.6 * * *$ \\
\hline No difficulties, $n$ (\%) & $159(57.0)$ & $175(46.5)$ & $\chi^{2}=65$, d.f. $=2 * * *$ \\
\hline I-2 difficulties, $n$ (\%) & $52(18.6)$ & $70(18.6)$ & \\
\hline$>2$ difficulties, $n$ (\%) & $66(23.7)$ & $|3|(34.8)$ & \\
\hline \multicolumn{4}{|l|}{ Lifestyle } \\
\hline BMI, kg/m²: mean (s.d.) & $22.6(2.9)$ & 22.2 & $t=-2.8^{* *}$ \\
\hline \multicolumn{4}{|l|}{ Physical activity ${ }^{2}$} \\
\hline Score: mean (s.d.) & $3.4(1.4)$ & $3.4(1.5)$ & $t=0.3$ \\
\hline Low, $n(\%)$ & $3 I$ (II.2) & $48(12.7)$ & $\chi^{2}=3$, d.f. $=2$ \\
\hline Moderate, $n$ (\%) & $106(38.4)$ & 145 (38.3) & \\
\hline High, $n(\%)$ & $139(50.4)$ & $186(49.1)$ & \\
\hline \multicolumn{4}{|l|}{ Alcohol consumption, $n$ (\%) } \\
\hline Never & $52(18.7)$ & $123(32.5)$ & $\chi^{2}=235^{* * *}$ \\
\hline Daily & $45(16.2)$ & $116(30.7)$ & d.f. $=3$ \\
\hline I-6 days a week & $77(27.7)$ & $76(20.1)$ & \\
\hline$<\mathrm{I}-3$ days a month & $104(37.4)$ & $63(16.7)$ & \\
\hline Currently smoking, n (\%) & $103(39.1)$ & $66(17.4)$ & $\chi^{2}=94 * * *$ \\
\hline
\end{tabular}

BMI, body mass index; COPD, chronic obstructive pulmonary disease; MMSE, Mini-Mental State Examination; OCD, obsessive-compulsive disorder

I. Ability to perform basic physical actions used in daily living

2. Range $0-5$ sum score of walking, bicycling, household activities (light and heavy), sports; $0-1$ low, 2-3 moderate,

2. Range

$* P<0.05, * * P<0.01, * * * P<0.001$. magnitude of the relation between anxiety and mortality; smoking, drinking and body mass index hardly affected it (Table 3). Adjustment for ongoing treatment status had no effect on the hazard ratios.

Finally, in the fully adjusted model, anxiety disorders had a hazard ratio for subsequent mortality in men of $1.78(95 \%$ CI 1.01-3.13) and in women of 0.89 (95\% CI 0.51-1.56) (Table 3). The survival curves according to the adjusted Cox model are shown in Fig. 1 for men and in Fig. 2 for women.

\section{DISCUSSION}

An association between anxiety disorders and subsequent mortality was found for men only. Older men with diagnosed anxiety disorders had $87 \%$ higher risk of mortality over 7 years of follow-up. The associations between anxiety and mortality in men remained after adjustment for comorbid depression, the explanatory variables (activity, smoking, drinking, body mass index) and confounders (age, psychiatric treatment, functional limitations and chronic diseases, including heart disease and stroke). In women with anxiety disorders no association was found with subsequent mortality.

\section{Explanations}

Several plausible mechanisms for the link between affective disorders and mortality exist, of which pathophysiological and behavioural explanations are the most important. Physiological alterations have been described which include impairment of platelet function and decreased heart rate variability as a consequence of an imbalance in the autonomic tone (Kawachi et al, 1995; Musselman et al, 1998). Also, immune activation and hypercortisolaemia as stress responses may result in decreased insulin resistance and increased steroid production and blood pressure, thereby increasing the risk of cardiac disease (Musselman et al, 1998). However, these studies investigated people with affective disorders, thus combining anxiety and depressive disorders. We are not aware of any pathophysiological study on specific anxiety disorders. It is likely that anxious people are less compliant with treatment recommendations and are less willing to exercise and eat healthily, which may partly explain our results (DiMatteo et al, 2000). 
Table 2 Anxiety cases, number of deceased, person-years and mortality rate at 7.5-year follow-up

\begin{tabular}{|c|c|c|c|c|c|}
\hline & $\begin{array}{c}\text { Total } \\
n\end{array}$ & $\begin{array}{c}\text { Cases } \\
n\end{array}$ & $\begin{array}{c}\text { Deaths } \\
n\end{array}$ & Person-years & $\begin{array}{c}\text { Mortality rate per } \\
1000 \text { person-years' } \\
(95 \% \mathrm{Cl})\end{array}$ \\
\hline All participants & 659 & & & & \\
\hline No anxiety disorder & & 547 & 164 & 3170 & $51.7(44.1-60.3)$ \\
\hline Anxiety disorder & & 112 & 35 & 626 & $55.9(38.9-77.8)$ \\
\hline Men & 279 & & & & \\
\hline No anxiety disorder & & 244 & 93 & 1350 & $68.9(55.6-84.4)$ \\
\hline Anxiety disorder & & 35 & 17 & 161 & $105.6(61.5-169.1)$ \\
\hline Women & 380 & & & & \\
\hline No anxiety disorder & & 303 & 71 & 1820 & 40.7 (3I.9-5I.0) \\
\hline Anxiety disorder & & 77 & 18 & 465 & $38.7(22.9-61.2)$ \\
\hline
\end{tabular}

I. (Deaths/person-years) $\times 1000$.

Table 3 Mortality risks for men and women with or without anxiety disorders at baseline

\begin{tabular}{|c|c|c|c|}
\hline & $\begin{array}{c}\text { Total }^{2} \\
n\end{array}$ & $\begin{array}{l}\text { Crude hazard ratio } \\
\text { Ratio }(95 \% \mathrm{Cl})\end{array}$ & $\begin{array}{c}\text { Adjusted hazard ratio' } \\
\text { Ratio }(95 \% \mathrm{Cl})\end{array}$ \\
\hline \multicolumn{4}{|l|}{ Men } \\
\hline I. No anxiety disorder & 222 & Reference & \\
\hline Anxiety disorder & 31 & $1.65(0.98-2.78)$ & $1.78(1.01-3.13)^{*}$ \\
\hline 2. Anxiety or depressive disorder & 42 & $1.77(1.10-2.83)^{*}$ & $2.41(1.36-4.25)^{*}$ \\
\hline 3. Anxiety and depressive disorders & 4 & -3 & -3 \\
\hline \multicolumn{4}{|l|}{ Women } \\
\hline I. No anxiety disorder & 297 & Reference & \\
\hline Anxiety disorder & 76 & $\mathrm{I} .00(0.59-\mathrm{I} .7 \mathrm{I})$ & $0.89(0.5 \mathrm{I}-\mathrm{I} .56)$ \\
\hline 2. Anxiety or depressive disorder & 96 & $0.95(0.58-1.56)$ & $0.63(0.3 \mathrm{I}-\mathrm{I} .28)$ \\
\hline 3. Anxiety and depressive disorders & 24 & $1.73(0.84-3.60)$ & $2.93(0.81-10.61)$ \\
\hline
\end{tabular}

I. Adjusted for age, physical limitations, physical activity, number of chronic diseases, ever smoked, alcohol, body mass index and comorbid depressive disorder (the last not in 2 and 3 ).

2. Totals differ between Tables 2 and 3 owing to missing data on one of the covariates in the model.

3. Number too small for reliable analysis.

$* P<0.05$.

A possible explanation for the gender difference is that men have more cardiovascular disorders, the course of which could be affected more strongly by comorbid anxiety. A psychological explanation might be that men are less capable of dealing with feelings of anxiety and hopelessness than women. Women are more inclined to discuss such feelings with others, are more open to accepting support from others, and may therefore be better able to cope with feelings of anxiety (Verbrugge, 1985). Also, men are less inclined than women to report feelings of anxiety. If they nevertheless do report them, their condition may be worse than that of their female counterparts, which can have a greater impact on their physical health and may lead to earlier death. Another explanation might be that anxious elderly men more often die by suicide than their female counterparts. However, causes of death were studied in our sample in an earlier account, but suicide did not explain the excess mortality (Penninx et al, 1999).

\section{Earlier studies}

The (weighted) prevalence of anxiety disorders in our study is comparable with other community-based studies among the elderly (Flint, 1994). Mortality figures for people with anxiety disorders in community-based samples are rare and conflicting. In a large German cohort study with 5 years of follow-up, anxiety symptoms were associated with improved survival (Hermann et al, 2000). In contrast, in a large community-dwelling cohort with a follow-up period of 17 years (Joukamaa

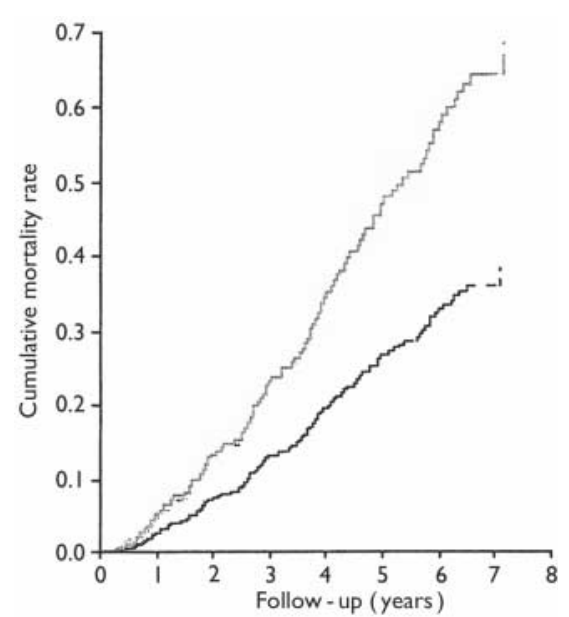

Fig. I Cumulative mortality rate for men with an anxiety disorder (grey line) and without an anxiety disorder (black line), based on fully adjusted Cox hazard models.

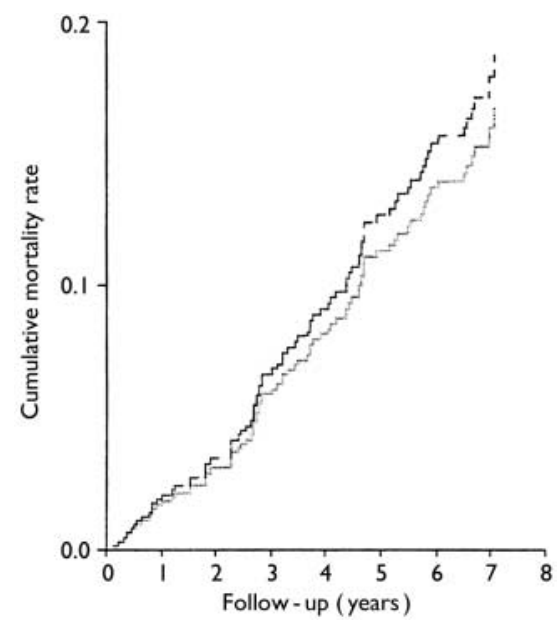

Fig. 2 Cumulative mortality rate for women with an anxiety disorder (grey line) and without an anxiety disorder (black line), based on fully adjusted Cox hazard models.

et al, 2001), the authors were unable to find significant associations between phobias and mortality rate. In an earlier study among in-patients with anxiety disorders excess mortality was reported, of which a third was due to suicide (Allgulander \& Lavori, 1991). Studies of out-patients with anxiety disorders confirmed the excess mortality but found a much lower suicide rate (Coryell, 1988; Johnsson Fridell et al, 1996; Warshaw et al, 2000). Two small US studies among out-patients with panic disorder reported a doubled mortality rate (Coryell et al, 1982; Weissman et al, 
1990). However, a confirmation study some years later by Coryell et al (1986) found less evidence for this relationship.

\section{Strengths and limitations}

Our study was the first to combine a long follow-up period (7.5 years) with formal diagnosis of anxiety in a general population sample and complete mortality data. Also, our extensive biological, psychological and sociological baseline measurements enabled identification and adjustment for confounders. A first limitation was that the diagnoses were based on DSM-III nosology; the results therefore cannot be extrapolated to people meeting DSM-IV criteria for anxiety disorders (American Psychiatric Association, 1994). This is especially relevant since a large portion of the sample were diagnosed with generalised anxiety disorder, for which the DSM-IV criteria are more stringent. Second, generalisation of our findings is limited by non-response; this was largely due to oversampling of the 'older old', who were more likely to withdraw from the study because of health problems, cognitive problems or death. Thus, the sample may underrepresent the frailest group, and generalisation of our findings to this section of the population is limited. However, for the study's purpose of investigating the associations between variables, good representation on all variables is far more important. Also, it should be noted that selective attrition of the most frail is more likely to have resulted in too conservative an estimate, rather than exaggerating the impact of anxiety on mortality. Third, with our data it is difficult to disentangle cause and effect: it remains unclear whether a worse health status leads to anxiety, or conversely whether anxiety leads to a worse health status and subsequent greater mortality. Finally, further analyses should take the cause of death into account as well. This might shed more light on the mechanism of increased mortality rates among men.

\section{Implications}

An important consequence of our findings for health policy is that it is important to treat anxiety in older people. In our study few elderly people with anxiety disorders received treatment. There are several treatment options available for anxiety disorders. Although there are only a few treatment effect studies among elderly

\section{CLINICAL IMPLICATIONS}

- A major consequence of our findings for health policy is that it is important to treat anxiety in older people.

- To increase the number of treated patients, better recognition and patient empowerment are key issues.

- The next steps for research would be to look into the causes of death associated with anxiety and to explore further sociopsychological and pathophysiological differences between men and women.

\section{LIMITATIONS}

- The diagnoses were based on DSM-III nosology and therefore our results cannot be extrapolated to people meeting current DSM-IV criteria for anxiety disorders.

- The sample may underrepresent the frailest individuals and generalisation of our findings to this portion of the population is limited.

- Our data make it difficult to disentangle cause and effect; it remains unclear whether a worse health status leads to anxiety, or conversely whether anxiety leads to a worse health status and subsequent mortality.

HEIN P. J. VAN HOUT, PhD, Department of General Practice, AARTJAN T. F. BEEKMAN, MD, PhD, Department of Psychiatry, Institute for Research in Extramural Medicine, VU University Medical Centre, Amsterdam; EDWIN DE BEURS, PhD, Department of Psychiatry, Leiden University Medical Centre, Leiden; HANNIE COMIJS, PhD, Department of Psychiatry, HARM VAN MARWIJK, MD, PhD, MARTEN DE HAAN, MD, PhD, Department of General Practice, WILLEM VAN TILBURG, MD, PhD, DORLY J. H. DEEG, PhD, Department of Psychiatry, Institute for Research in Extramural Medicine, VU University Medical Centre, Amsterdam, The Netherlands

Correspondence: Mr Hein van Hout, Department of General Practice, Institute for Research in Extramural Medicine, VU University Medical Centre, Van der Boechorststraat 7, 108I BTAmsterdam, The Netherlands. Tel: +31 20 4448199; fax: +31 20 444836I ; e-mail: Hpj.vanhout@vumc.nl

(First received I5 September 2003, final revision 16 April 2004, accepted 3I May 2004)

people, there is no reason to expect the efficacy of treatment to diminish with age. The next steps for research are to look into the causes of death associated with anxiety, to explore further the sociopsychological and pathophysiological differences between men and women, and to test the effect of interventions.

\section{ACKNOWLEDGEMENT}

This research was primarily funded by the Ministry of Health Welfare and Sports.

\section{REFERENCES}

Allgulander, C. \& Lavori, P.W. (1991) Excess mortality among 3302 patients with 'pure' anxiety neurosis. Archives of General Psychiatry, 48, 599-602.
American Psychiatric Association (1980) Diagnostic and Statistical Manual of Mental Disorders (3rd edn) (DSM-III). Washington, DC: APA.

American Psychiatric Association (1994) Diagnostic and Statistical Manual of Mental Disorders (4th edn) (DSM-IV). Washington, DC: APA.

Beekman, A.T., Bremmer, M. A., Deeg, D. J., et al (1998) Anxiety disorders in later life: a report from the Longitudinal Aging Study Amsterdam. International Journal of Geriatric Psychiatry, 13, 717-726.

Beekman, A. T., Deeg, D. J., Smit, J. H., et al (1995a) Predicting the course of depression in the older population: results from a community-based study in The Netherlands. Journal of Affective Disorders, 34, $4 \mid-49$.

Beekman, A.T., Deeg, D. J., vanTilburg, T., et al (1995b) Major and minor depression in later life: a study of prevalence and risk factors. Journal of Affective Disorders, 36, 65-75.

Coryell, W. (1988) Panic disorder and mortality. Psychiatric Clinics of North America, II, 433-404. 
Coryell, W., Noyes, R. \& Clancy, J. (1982) Excess mortality in panic disorder. A comparison with primary unipolar depression. Archives of General Psychiatry, 39. 70I-703.

Coryell, W., Noyes, R. \& House, J. D. (1986) Mortality among outpatients with anxiety disorders. American Journal of Psychiatry, 43, 508-510.

Cuijpers, P. (200I) Mortality and depressive symptom in inhabitants of residential homes. International Journal of Geriatric Psychiatry, 16, I31-138.

de Beurs, E., Beekman, A.T., van Balkom, A. J., et o (1999) Consequences of anxiety in older persons: its effect on disability, well-being and use of health services. Psychological Medicine, 29, 583-593.

DiMatteo, M. R., Lepper, H. S. \& Croghan, T.W. (2000) Depression is a risk factor for noncompliance with medical treatment: meta-analysis of the effects of anxiety and depression on patient adherence. Archives of Internal Medicine, 160, 2101-2107.

Duncan-Jones, P. \& Henderson, S. (1978) The use of two-phase design in a prevalence survey. Social Psychiatry, 13, 231-237.

Flint, A. J. (1994) Epidemiology and comorbidity of anxiety disorders in the elderly. American Journal of Psychiatry, I5I, 640-649.

Folstein, M. F., Folstein, S. E. \& McHugh, P. R. (1975) 'Mini-Mental State': a practical method for grading the cognitive state of patients for the clinician. Journal of Psychiatric Research, 12, 189-198.

Geerlings, S. W., Beekman, A. T., Deeg, D. J., et o (2000) Physical health and the onset and persistence of depression in older adults: an eight-wave prospective community-based study. Psychological Medicine, 30 369-380.

Herrmann, C., Brand-Driehorst, S., Buss, U., et al (2000) Effects of anxiety and depression on 5-year mortality in 5,057 patients referred for exercise testing. Journal of Psychosomatic Research, 48, 455-462.

Honig, A., Pop, P., de Kemp, E., et al (1992) Physical illness in chronic psychiatric patients from a community psychiatric unit revisited. A three-year follow-up study. British Journal of Psychiatry, 16I, 80-83.

Johnson, J., Weissman, M. M. \& Klerman, G. L. (1990) Panic disorder, comorbidity, and suicide attempts. Archives of General Psychiatry, 47, 805-808.

Johnsson Fridell, E., Ojehagen, A. \& TraskmanBendz, L. (1996) A 5-year follow-up study of suicide attempts. Acta Psychiatrica Scandinavica, 93, 151-157.

Joukamaa, M., Heliövaara, M., Knekt, P., et al (200I) Mental disorders and cause-specific mortality. British Journal of Psychiatry, 179, 498-502.

Kawachi, I., Sparrow, D., Vokonas, P. S., et al (1995) Decreased heart rate variability in men with phobic anxiety (data from the Normative Aging Study). American Journal of Cardiology, 75, 882-885.

Kriegsman, D. M., Penninx, B.W., van Eijk, J.T., et a (1996) Self-reports and general practitioner information on the presence of chronic diseases in community dwelling elderly. A study on the accuracy of patients' selfreports and on determinants of inaccuracy. Journal of Clinical Epidemiology, 49, 1407-1417.

Lasser, K., Boyd, J. W., Woolhandler, S., et al (2000) Smoking and mental illness: a population-based prevalence study. JAMA, 284, 2606-2610.

Musselman, D. L., Evans, D. L. \& Nemeroff, C. B. (1998) The relationship of depression to cardiovascular disease: epidemiology, biology, and treatment. Archives of General Psychiatry, 55, 580-592.

Penninx, B.W., Geerlings, S.W., Deeg, D. J., et al (1999) Minor and major depression and the risk of death in older persons. Archives of General Psychiatry, 56, 889-895.
Radloff, L. S. (1977) The CES-D Scale: a self-report depression scale for research in the general population. Journal of Applied Psychological Measurement, I, 385-40I.

Robins, L. N., Helzer, J. E., Croughan, J., et al (198I) National Institute of Mental Health Diagnostic Interview Schedule. Its history, characteristics, and validity. Archives of General Psychiatry, 38, 38I-389.

Van Exel, E., Stek, M. L., Deeg, D. J., et al (2000) The implication of selection bias in clinical studies of late life depression: an empirical approach. International Journal of Psychiatry, 15, 488-492.

van Sonsbeek, J. L. A. (1988) Methodological and content related aspects of the OECD indicator of chronic functional limitations. Maandbericht Gezondheid, 88 4-17.

van Tilburg, T., Dykstra, P., Liebroer, A. C., et a (1995) Sourcebook of Living Arrangements and Social Networks of Older Adults in the Netherlands. Amsterdam: VU University Press.

Verbrugge, L. M. (1985) Gender and health - an update on hypotheses and evidence. Journal of Health and Social Behaviour, 26, 156-182.

Visser, M., Launer, L. J., Deurenberg, P., et al (1997) Total and sports activity in older men and women: relation with body fat distribution. American Journal of Epidemiology, 145, 752-76

Warshaw, M. G., Dolan, R. T. \& Keller, M. B. (2000) Suicidal behavior in patients with current or past panic disorder: five years of prospective data from the Harvard/Brown Anxiety Research Program. American Journal of Psychiatry, 157, 1876-1878.

Weissman, M. M., Markowitz, J. S., Ouellette, R., et al (1990) Panic disorder and cardiovascular/ cerebrovascular problems: results from a community survey. American Journal of Psychiatry, 147, 1504-1508. 